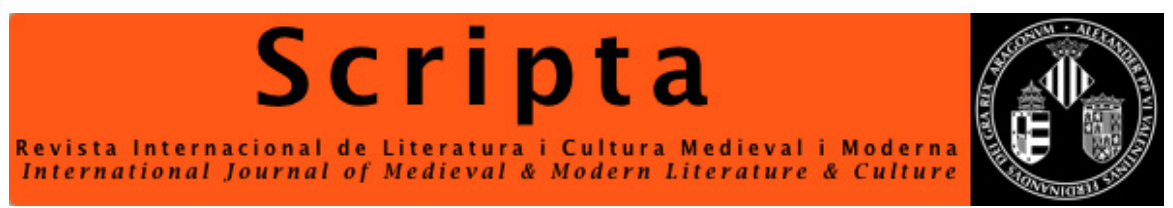

\title{
Èsquil al Curial e Güelfa
}

\author{
Aeschylus in Curial e Güelfa
}

\author{
JORDI REDONDO \\ jordi.redondo@valencia.edu
}

Universitat de València

Resumen: El llibre III de la novella pre-renaixentista Curial e Guelfa presenta les característiques d'una prosa deutora en un alt grau de l'humanisme. Elements destacats en són la dicció mitològica, la ubicació de part dels esdeveniments i la imitació de models literaris clàssics. Al present treball mirem d'escatir fins a quin punt la tragèdia d'Èsquil on es representava el judici d'Orestes, les Eumènides, ha pogut esdevenir el model per al judici de Curial al Parnàs, com anys enrera va proposar Patricia Boehne. D'acord amb unes premisses metodològiques diferents de les d'ella, basem les nostres conclusions en les relacions intertextuals establertes entre ambdues obres.

Palabras clave: Tradició clàssica, Èsquil, Curial e Güelfa, judici, Eumènides.

Abstract: The third book of the pre-Renaissance novel Curial e Güelfa shows the features of a prose deeply indebted with Humanism. Noteworthy elements of this influence are the mythological discourse, the setting of a huge part of the events, and the imitation of Classical literary models. In this paper we aim to elucidate to what a extent, if there was such an imitation, the Aeschylean tragedy in which was put on stage the trial of Orestes, the Eumenides, could become the literary model for the trial of Curial at the Parnasse, as was some years ago suggested by Patricia Boehne. After different methodological premises from her's, we base our conclusions on the intertextual relations established between both texts.

Keywords: Classical tradition, Aeschylus, Curial e Güelfa, trial, Eumenides. 


\section{El Curial e Güelfa i les Eumènides d'Èsquil. La tesi de Boehne i la figura de Giovanni Aurispa}

Un dels capítols més interessants dins el Curial e Güelfa és el titulat El judici de Curial, al llibre III (Aramon i Serra 1933: 81-91), precisament la part de l'obra on la influència de les literatures antigues es fa més palesa, i que a sobre l'autor situa a l'escenari del Parnàs. Per consegüent, la intencionalitat no deixa lloc al dubte. Juntament amb el desplegament d'un relat amarat de referències mitològiques i l'evocació de la cultura clàssica mitjançant l'escenari mateix de la muntanya de les Muses, caldria esperar que l'autor de la novella mostrés també la inclusió de motius literaris manllevats a la tradició greco-llatina.

A la seua monografia sobre el gènere, Patricia Boehne ha plantejat el conjunt del capítol com una transposició del judici d'Orestes a l'obra d'Èsquil que tanca la trilogia, les Eumènides (Boehne 1989: 77-78). ${ }^{1}$ Com que aquesta tragèdia no hauria estat coneguda a Europa occidental fins a ço que la hi va dur l'humanista Giovanni Aurispa, l'any 1423, Boehne situa la composició del Curial e Güelfa, o d'una part d'ell almenys, a la Itàlia de mitjan segle XV i en contacte amb els cercles d'ensenyament del grec de Bolonya, Florència i Ferrara. ${ }^{2}$ El còdex a què es refereix Boehne es el Laurentianus 32.9, de mitjan segle $\mathrm{X}$, adquirit per Aurispa a Constantinoble entre molts altres manuscrits, per encàrrec del príncep Niccolò III d'Este, senyor de Ferrara, que el va comissionar per a un viatge a Grècia entre el 1421 i el 1423. El còdex fou després adquirit per l'humanista florentí Niccolò Niccoli l'any 1424, i llegat després al príncep Cosimo de' Medici, d'acord amb el testament del mateix Niccoli, traspassat el $1437^{3}$; el 1444 Gonzalo Manetti, com a curador del testament, va dipositar bona part de la biblioteca de Niccoli al monestir de San Marco, a la ciutat de l'Arno. ${ }^{4}$

\footnotetext{
1 Entre nosaltres ha estat més coneguda una versió anterior, molt breu (Boehne 1982). Aquest treball va merèixer una rotunda desqualificació per part de Badia (1986: 7, n. 10): «S’hauria de continuar per aquest camí i no, naturalment, pel que emprèn al meu entendre temeràriament P.J. Boehne (...) (pretèn de relacionar el nostre text amb les Eumènides d'Èsquil)».
}

2 Cf. Boehne (1989: 78-79): «The first known version of The Eumenides outside of Greece was a Greek manuscript from the year 1000. A Sicilian, Giovanni Aurispa, had bought it and transmitted it to Niccolò Niccoli in Florence about 1423. We have no record of The Eumenides until the 'princeps' edition in 1518, in Venice. However, there were other manuscript copies in Greek, probably from Demetrius Triclinius (b. 1280). There is a Salamanca manuscript in Greek from the thirteenth or fourteenth century, and a few others were scattered about parts of northern Europe, including Milan. It would seem impossible that an older Catalan soldier just beginning his academic studies could have known the work in the original Greek, and no Latin version was known. One possibility is that the aforementioned Sicilian, Aurispa, or an associate of his, had personal contact with the author. Aurispa died in 1459, and during the last years of his life earned his living as a teacher of language and literature in Bologna, Florence, and Ferrara. Did our author know Aurispa? The dates lend plausibility: Aurispa died in 1459, Curial e Guelfa appeared about 1460, and all the novel's classical elements appear in book 3, being present in the final part of the text. Both the author of Curial and Aurispa were in Italy, in the territories of the kingdom of Aragon, and the former admittedly studied the classics and the muses in his latest years».

3 Vegeu al respecte Ullmann \& Stadter (1972: 259-309). S’ho val a recordar que la collecció bibliogràfica d'aquest monestir va esdevenir el pinyol de l'actual Biblioteca Nazionale Italiana.

4 Resulta simplement decebedor que a una recent monografia sobre la recepció d’Èsquil (Futo Kennedy (ed.) 2017)

SCRIPTA, Revista internacional de literatura i cultura medieval i moderna, núm. 11 / juny 2018 / pp. 22-34

ISSN: $2340-4841 \cdot$ doi:10.7203/SCRIPTA.11.12583 
Si la tesi de Boehne és correcta, gran part del deute de la novella amb la literatura i la mitologia clàssiques es deuria a la relació del seu autor amb el cercle d'Aurispa. Existia, però, aquest cercle? Qui el formava? I qui era aquest personatge? Creiem necessària per a la recerca present una aproximació més detallada envers Giovanni Aurispa, el qual considerem una figura clau en la penetració de les literatures antigues dins la cultura de llengua catalana. ${ }^{5}$

Nat a la vila siciliana de Noto cap al 1376 segons Sabbadini - per bé que la data no és encara segura, Giovanni Pichuneri -Picciuneri segons l'ortografia toscana-, conegut més tard amb el renom d'Aurispa, va iniciar la seua formació a Nàpols; l'any 1404 va estar becat pel rei Martí l'Humà perquè seguís els estudis de dret a Bolonya, amb la qual cosa iniciava una llarga carrera de vinculació i de servei a la corona catalana. Va fer també estudis a Florència, on fou alumne dels cursos de llengua grega instituïts des del 1397 per Manuil Crisoloràs. ${ }^{7}$ No sembla que fos hellenoparlant nadiu, però no descartem que ho fossin els seus avantpassats, a la mateixa illa de Sicília, atès que la vall de Noto fou una de les contrades on més va resistir l'ús de la llengua. Entre els anys 1413 i 1414 féu un primer viatge a Grècia i hi va aprendre la llengua, a més de fer els primers contactes personals i obtenir els primers còdexs. Només amb un dels seus viatges, esdevingut entre els anys 1421 i 1423, es va fer amb dos-cents-trenta-vuit còdexs (Schreiner 1994), que va haver d'empenyorar a Venècia per cinquanta florins d'or, i que el mecenes Cosimo de' Medici va adquirir després, alhora que cridava a la seua cort Aurispa. Es va establir a Savona, on va fer diners amb el comerç librari. Ja des del 1419 el trobàvem al servei del Papat, que li encarregà diverses missions a Grècia, on arreplegava nous còdexs. A Itàlia combinava la docència a la Universitat de Florència amb el comerç dels manuscrits. Entre el 1424 i el 1425 va traduir el dotzè Diàleg dels morts de Llucià, i per la mateixa època comptava entre els seus deixebles Lorenzo Valla, el més gran dels humanistes del renaixement italià. Entre els seus clients com a marxant de llibres hi hagué la famíllia més poderosa de l"època, els Este de Ferrara, que el varen convèncer perquè el 1427 esdevingués preceptor de Meliaduse, fill natural de Niccolò III. Aurispa rebia el 1429 els ordes sacerdotals a la mateixa Ferrara, on es va establir. Entre el 1429 i el 1430 traduïa el Tòxaris de Llucià. No va estar fins al 1440 que se li va atorgar una renda notable, el benefici de l'església de Santa Maria in Vado, molt a prop de la seu de la Universitat. A les quatre-centes lliures s'afegia el nomenament d'un capellà auxiliar que s'encarregava de la major part

no es dediqui ni una línia a l'arribada a Itàlia d'aquest manuscrit -se’n dóna una breu notícia (Simelidis 2017: 183-185), però tan sols sobre la seua relació amb la filologia bizantina- i al seu paper dins la difusió de l'obra d’Èsquil a Europa occidental.

5 Sobre la figura i l'obra de Giovanni Aurispa, vegeu Ortolani et al. (1818: 19-22), que situa naixement i decés els anys 1369 i 1459; Franceschini (1976); Giannini (1973); Sabbadini (1890 i 1931); Schreiner (1994); Salvo Cozzo (1891).

6 Vegeu Sabbadini (1890: IX), el qual tanmateix no descarta que fos nat cap al 1372. S’han proposat també datacions més altes, cap al 1370. De fet, el decés d'Aurispa el 1459 quan tenia vora noranta anys apuntaria cap al 1369 com a data del seu naixement.

7 Geanakoplos (1989: 40): «(...) The event which marks the first systematic teaching of Greek language and literature in the West was the arrival in Florence of the aristocratic Byzantine Manuel Chrysoloras to teach at that city's studium». 
dels oficis religiosos (Franceschini 1976: 9-10). De la seua vida personal val a ressenyar que amb la seua serventa, presentada adés com a siciliana, adés com a tàrtara -o sigui, turca-, bé amb el nom de Magdalena o amb el seu nadiu, havia tingut tres fills, tots ells reconeguts abans del seu traspàs a Roma, el 1459, tot just un any abans de la publicació del Curial e Güelfa.

Com a humanista, Aurispa no es mostra gaire eficient: en conservem les versions llatines del comentari d'Hièrocles d'Alexandria als Versos auris de Pitàgores i de la Carta de condol a Ciceró de Filisc, tramesa per Dió Cassi; hem indicat adés les traduccions d'opuscles de Llucià. Se li atribueixen també traduccions d'Arquímedes. Nosaltres, tanmateix, hem trobat noves referències que completen el retrat de l'Aurispa humanista. El còdex 47, un manuscrit del segle XV, de la Biblioteca Guarneriana de San Daniele dei Friuli conté l'obra Ad Baptistam equitem romanum ex patriciis de Capite de ferro Potestatem Bononie Comparatio apud inferos trium Imperatorum videlicet Scipionis, Alexandri et Annibalis, l'autoria de la qual es veu inequívocament explicitada mitjançant un eloqüent per Aurispam. Com hi va arribar no sembla gens inextricable: el 1466 Guarnerio d'Artegna va fer a la vila un llegat de cent setanta-tres còdexs, gran part dels quals es devien a les seues magnífiques relacions amb grans humanistes d'aquell temps -Lorenzo Valla, Leonardo Bruni, Guarino Veronese, etc.- (Casarsa, D’Angelo \& Scalon 1999). També es deu al nostre Aurispa la traducció de les Cartes d'Hipòcrates, conservades al manuscrit Ms. Lat. class. e. 19 de la Bodleian Library de la Universitat d'Oxford. ${ }^{8}$ Probablement es tracta de l'encàrrec fet per algun professional de la medicina.

Aurispa era molt pagat del seu tresor bibliogràfic, del qual deia que era ben bé la seua sola possessió material, alhora que es vantava que no hi havia a tota Itàlia una altra biblioteca com la seua. ${ }^{9}$ Fou no només un humanista, ans un colleccionista compulsiu de còdexs grecs i llatins, dels quals va acumular el que al seu temps seria ben bé una de les més completes biblioteques d'Europa occidental. Sabem també que Aurispa, que vivia a prop de Santa Maria in Vado, protegia a Ferrara un cert grup d'humanistes, entre els quals alguns de sicilians i en especial de Noto (Sabbadini 1890: 11); les rendes

8 Val a assenyalar que el manuscrit, del segle XVI, conté també la traducció del tractat aristotèlic Sobre la virtut per Teodor de Gaza, un protegit d'Aurispa. Quan el 1455, a la mort del seu protector, el Papa Nicolau V, Teodor de Gaza va deixar Roma, es va installar a Nàpols acollit per Alfons el Magnànim, que el va hostatjar a l'abadia de Trepergole, vora Pozzuoli. Fou el nostre humanista sicilià qui el va recomanar, segons que confirma la carta d'Antonio Panormita a l'Aurispa, datada a Nàpols el novembre del 1455 (Sabbadini 1890: 139 i n. 2): «Theodorum tuum, quem mihi tantopere comendas, scito apud Alphonsum regem magnifice collocatum». S'ho val de parar esment a la resposta de Giovanni Aurispa, tramesa des de Roma el mes següent, cf. Sabbadini (1931: 140): «Quod Theodorum bene et feliciter apud Alphonsum regem collocaris, officium tuum exercuisti, nam doctorum hominum est doctis benefacere et fauere. Praeterea, quod forte tibi non in mentem uenit, necessarius iste uir maxime regi erit, si ad recuperandam Constantinopolim, ut aiunt, et Christi fidem resarciendam iturus est: dissuitur enim atque utinam non laceretur. Nusquam linguarum interpretem, quo rex praecipue egebit, Theodoro aptiorem inueniet». Malauradament, el rei Alfons va finar el 1458, i el projecte de croada contra els turcs es va extingir amb ell.

9 L'orgull del colleccionista satisfet amb el seu tresor es trasllueix a la carta d'Aurispa a Niccolò Speciale, datada a Bolonya l'1 de Novembre del 1437 (Sabbadini 1931: 91): «Fuit mibi iam a puero noluptuosum naria multaque legere. Quae res tantam mibi cupiditatem habendi codices intulit, ut librorum possessionem rebus omnibus praetulerim. Quo factum est, ut nibil aliud habeam praeter codices, quorum mibi tanta multitudo est, ut nulla in Italia hodie bibliotheca sit quam mea non superet». 
del nostre personatge no bastaven per sostenir aquestes despeses, que en bona mesura sufragaven d'altres mecenes ferraresos, com la família dels Benzi (Sabbadini 1890: 12) -cal fer una menció especial a Ugo Benzi, metge de cort de la casa d'Este abans de l'arribada de Michele Savonarola-, o humanistes com Guarino Veronese (Sabbadini 1890: 13). Al mateix temps, Aurispa mantenia relacions, tant personals com acadèmiques, amb la pràctica totalitat dels grans humanistes italians, $i$ en especial, cap als darrers anys de la vida del nostre personatge, amb els que havia congregat el rei Alfons el Magnànim a Nàpols. Així ho indiquen la fluïda relació epistolar amb el monarca mateix i ensems la tramesa de còdexs, ${ }^{10}$ a més de la seua familiaritat amb personatges de la cort, com ara el secretari del rei, Joan Olzina. ${ }^{11}$ No sembla forassenyat de suggerir que aquest gran marxant de còdexs grecs a Itàlia, Giovanni Aurispa, súbdit de la Corona, pagat pel rei Martí i al servei més tard del rei Alfons, va fornir la biblioteca reial de manuscrits, tant grecs com llatins, part dels quals hauria passat després a les biblioteques d'altres magnats del regne. Que la circulació de còdexs entre Nàpols i València, posem per cas, era important tant per la quantitat com per la qualitat, ho confirma la col.lecció del duc de Calàbria, on es troben, per exemple, el códex 398 de la Biblioteca Universitària de l'Estudi General de València, amb les Satyrae de Francesco Filelfo, i el còdex 408, amb el Liber Elegantiarum de Lorenzo Valla.

Hi ha, però, una altra dimensió de l'activitat de l'Aurispa: es tracta del seu paper com a agent del rei Alfons, amb la comesa d'afavorir els seus interessos dins Itàlia. ${ }^{12}$ Poc abans que tingués lloc el concili de Ferrara, Aurispa hi va conèixer el bisbe de Lleida, Domingo Ram i Lanaja, que li va causar una impressió molt favorable. ${ }^{13}$

10 Sobre la tramesa de còdexs, vegeu la carta a Lorenzo Valla, escrita a Ferrara el desembre del 1443, on li pregunta què se n’ha fet de la Institutio oratoria de Quintilià (Sabbadini 1931: 101): «Quintilianum quem ad te iam pridem misi nescius sum an acceperis, nihil enim ea quoque de re ad me scripsisti; feceris igitur mihi gratissimum si me de ea re certiorem reddideris». Una tramesa més generosa és esmentada a la carta a Antonio Panormita, datada a Roma el 28 d'agost del 1457 (Sabbadini 1931: 148): «Misi per Iacobum Sores, [Diego Suárez] si nominis recte meminerim, diuo Alphonso Firmicum Siculum De Horoscopo, codicem pulchrum et preciosum; est enim auctor probatissimus et eloquens. Misi et Naturales auditus Aristotelis in graeco. Nunquam mihi responsum fuit. Firmicum latinum auctorem et speciosum dono dedi; Aristotelem postulauit rex accomodari maiestati suae, quem ego si acceptabat etiam largiebar. Redde me certiorem an hi codices regi dati fuerunt».

11 Carta a L. Valla (Sabbadini 1931: 101): «Nunc abs te peto, et etiam atque etiam oro, ut his omnibus regiae maiestatis familliaribus atque amicis, quos aut alique mecum familiaritate coniunctos aut beniuolentia quouis modo affectos scies, pro personarum dignitate accuratissime $<$ me $>$ commendes: incipies autem a magnifico d. Ioanne Olzina, quem ego, propter singulares eius uirtutes, ante alios amo, colo, obseruo». Sobre la figura de Joan Olzina, mecenes de literats i humanistes, cf. Mancini (1891: 202).

12 L’Aurispa, tot i la seua discreció, arriba a manifestar amb claredat aquesta comesa. A la carta a Niccolò Speciale, de Bolonya estant a 1 de Novembre del 1437, comenta els seus afanys per canviar la mala imatge dels catalans (Sabbadini 1931: 90): «Si quos ergo indefensos regi aduerto, reddo beneuolos, quamuis hoc quidem pro eius natura facile est. Neminem adhuc inueni, qui uerbum aliquod durum contra regiam maiestatem diceret. Genus horum citeriorum Hispanorum indefensum habent. Odium ego et inuidiam erga illos homines quantum possum diminuo».

13 A la mateixa carta a Nicolò Speciale (Sabbadini 1931: 90) llegim: «Praedico enim et singulares uirtutes regis, fuique

SCRIPTA, Revista internacional de literatura i cultura medieval i moderna, núm. 11 / juny 2018 / pp. 22-34 ISSN: 2340-4841 · doi:10.7203/SCRIPTA.11.12583 
El manuscrit d'Èsquil, molt valuós pel que fa a la transmissió d'aquest tràgic (Dawe 1964: 12), apareix a l'inventari dels béns d'Aurispa, ${ }^{14} \mathrm{i}$ val a suposar que aquest no se n'hauria desprès mai, conscient com seria de la raresa del text a Occident. Per una carta del posseïdor d'aquesta joia sabem que era seu en data anterior al $1423 .{ }^{15}$ Tanmateix, el Laurentianus 32.9 no va ésser l'únic manuscrit d'Èsquil conegut a la Itàlia renaixentista. Un altre còdex, aquest amb les obres dels tres tràgics, el consignat a la Biblioteca Marziana com a Gr. Z. 468 (= 653), figurava entre els béns del cardenal Bessarió, ${ }^{16}$ que volia traduir-lo.

\section{L'anàlisi del Curial e Güelfa en comparació amb les Eumènides.}

Per la seua datació, el Curial e Güelfa pot perfectament haver recollit la influència d’Èsquil, un cop reiniciada la seua introducció dins la cultura literària de l'Europa occidental. Recordem que ja l'estudi d'Espadaler assenyalava Jaume Perpunter com a autor de la novella, entre els anys 1456 i 1458 (Espadaler 1984). Dins l'obra, el llibre III presenta les característiques d'una prosa tocada per l'humanisme. No es tracta només del recurs a la dicció mitològica; l'autor de l'obra arriba fins i tot a fer excursos sobre etimologia, quan deriva el terme grec Moṽ $\sigma \alpha$ d'un hipotetic * ${ }_{\mu}$ ov $\varsigma$ amb el significat d'aigua. Potser l'autor pensava en les dones d'aigua com un equivalent del que haurien estat les Muses a l'Antiguitat. Hom podria pensar que per a l'elaboració d'aquesta etimologia hauria pogut tenir present Hesíode, però la font n'és un passatge de Boccaccio. ${ }^{17}$

El text d'Ėsquil on trobem el judici d'Orestes davant el tribunal de l'Areòpag d'Atenes, presidit per la deessa Atena, ocupa la pràctica totalitat de la tragèdia Les Eumènides. Segons Boehne les similituds amb el Curial són les següents:

1.- Els dos textos situen l'acció al mateix indret, el temple d'Apollo.

2.- L'heroi és víctima d'una acusació greu. Aquí no es dóna el parallel adduït, per tal com Curial és instituït jutge de la contesa.

curiosus, ut a multis eas audirem et audiui quidem saepe et a plerisque et praecipue a domino Ilerdensi, uiro sapienti et rerum humanarum peritissimo». La carta havia sigut prèviament editada per Malvica (1833: 145-149).

14 Vegeu Franceschini (1976: 61), a propòsit del còdex amb la referència 18 de l’inventari: «Item Eschillus, scriptus litteris grecis, in carta papiri, cum albis corei rubeì).

15 Vegeu a Sabbadini (1931: 163) la carta XVIII de l'apèndix, escrita per Ambrogio Traversari a Niccolò Niccoli el 1424, on comenta com Aurispa havia tramès el còdex a Florència l'any anterior.

16 La collecció personal de còdexs -quatre-cents vuitanta-dos de grecs, i dos-cents seixanta-quatre de llatins, el 1468que el cardenal Bessarió, finat el 1472, va llegar a la República de Venècia constitueix el fons més important reunit a Occident al segle XV, i va esdevenir la Biblioteca Marziana. Vegeu al respecte Mioni (1968).

17 Boccaccio, Gen. Deor. XI 2: «Nec non arbitror Musas a moys, quod est aqua, dictas, causa in sequentibus ostendetur». 
3.- Ambdós herois serien perseguits en justícia, i tots dos per les Erínies -Boehne, que les anomena Fúries, hi afegeix al cas de Curial la Fortuna-, però el plantejament no és correcte perquè l'heroi de la novella catalana apareix, insistim, com a jutge i no pas com a acusat.

4.- L'actuació dels respectius déus protectors, Apollo i Hermes en el cas d'Orestes, i Apollo i l'heroi Hèctor en el de Curial, aconsegueix de rebutjar les acusacions.

5.- Els dos protagonistes són caracteritzats amb una corona, la d'Orestes de fulles de vinya i la Curial de fulles de llorer.

6.- Boehne afegeix com a tema recurrent el fet que tots dos protagonistes són asseguts, aspecte talment trivial que no hi entrarem.

7.- Que els acompanyants es trobin endormiscats sí que sembla rellevant, encara que siguin les Erínies a les Eumènides i els companys de Curial a la novella.

8.- Els vots emesos són dotze en cada cas, ciutadans atenesos a les Eumènides, i les Muses amb l'afegitó d'Homer, Dares i Dictis, a la novella. ${ }^{18}$

Parallels entre ambdues obres dignes de consideració són els dels epígrafs 1), 4), 5), 7) i 8), mentre que la resta, tot i les argumentacions de Boehne, no afegeixen res en favor de la recepció d'Èsquil a la novella catalana. Aquests cinc ítems no resulten plenament convincents. Per exemple, i pel que fa a l'escenari, a les Eumènides l'acció principal no transcorre al temple d'Apollo a Delfos, sinó al d'Atenea a l'Acròpolis d'Atenes. Només l'escena inicial té el temple d'Apollo com a escenari. Tanmateix, cinc motius semblen suficients per a parlar d'una influència clara de les Eumènides sobre el Curial e Güelfa. Endemés, la convergència dels quatre motius actua com a element dinamitzador en ell mateix de la recepció de la tragèdia esquília a la novella. No hi ha cap més manera d'explicar la localització del judici al temple d'Apollo, el paper d'aquest mateix déu com a advocat defensor dels dos joves, la coronació de tots dos i l'endormiscament dels seguicis de l'un i l'altre.

\footnotetext{
18 Boehne (1989: 77-78): «The striking similarities of the two episodes may be summarized thus. Both take place at the temple of Apollo; both Orestes and Curial are pursued, Orestes by Clitemnestra and the Furies, Curial by Fortuna and the Furies; the pursuers are ineffectual, partly because they do not receive the help of other deities and partly because Curial and Orestes are protected, respectively, by Apollo and Hector, and by Apollo and Hermes. Orestes is crowned with a wreath and white wool, while Curial is crowned with a wreath and inscribed parchment. Both are seated for the judgment. The Furies sleep in The Eumenides and Curial's men lie down from fear just as the priestess' legs failed and Curial's did at the close of his coronation scene. Orestes is confronted with twelve Athenians, Curial with nine muses and three authors. The vote on Orestes' case is even, Curial's judgments are fairs and equal, and all present are both satisfied and justified at the close».
} 


\section{Els elements d'intertextualitat: la baula imprescindible.}

Hi ha, però, un element de més gran importància que la coincidència en uns determinats temes: es tracta dels reflexos d'una relació intertextual on, evidentment, la font és la tragèdia grega. És aquí on entra en escena la ciència filològica, que descansa en la mera exposició dels textos, i queda en segon pla la interpretació dels passatges. Ara bé, hem de fer una precisió metodològica important, com ho és el fet que la hipotètica influència de l'obra grega sobre la catalana no passaria per una intertextualitat directa, ans hauria comptat amb la intermediació d'una traducció; altrament caldria suposar que l'autor de la novella era capaç de llegir el grec d’Èsquil, el que no resulta versemblant. Admetem com a probable, doncs, l'existència d'una traducció llatina.

El primer passatge de les Eumènides que anem a considerar és el que segons Boehne parla de la coronació d'Orestes amb una garlanda -Orestes is crowned with a wreath and white wool-:

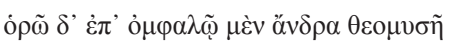

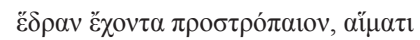

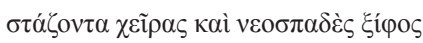

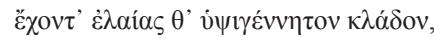

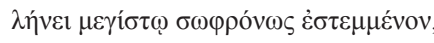

$$
\begin{aligned}
& \dot{\alpha} \rho \gamma \tilde{\eta} \tau \iota \mu \alpha \lambda \lambda \tilde{\omega} \cdot \tau \tilde{\eta} \delta \varepsilon \gamma \alpha \grave{\alpha} \rho \tau \rho \alpha \tilde{\omega} \varsigma \dot{\varepsilon} \rho \tilde{\omega} .
\end{aligned}
$$

(A.Eum. vv. 40-45)

Veig tot just dalt de l'ómphalos un baró avorrit pels déus, que pren seient a tall de suplicant, que de les mans destilla un degotim de sang $i$ branda una espasa que fen una ferida fresca, $\boldsymbol{i}$ alhora una branca d'olivera nada dalt de tot de l'arbre, castament coronada amb immens floc d'immaculada llana; aixi en diré d'una manera aguda.

El text del Curial e Güelfa que reflectiria el d’Èsquil és com segueix:

\footnotetext{
E axí, Achilles e Homero s'apartaren e meteren-se entre aquells llorers, e començà Achilles molt dolçament a cantar; $e$ Achilles, com emperador, e Homero, com a poeta, se coronaren dels rams d'aquells arbres a aquell déu consagrats (Aramon i Serra 1933: III 84).
}

La diferència entre l'olivera i el llorer sembla secundària si abans de res tenim en compte que Orestes porta un ram de suplicant, mentre que Aquilles i Homer duen corones que assenyalen llur autoritat, reial el primer i artística el segon. Es tracta de funcions sense cap relació, i si admetem que es dóna al Curial un cas de recepció, seria una de mancada d'un clar suport textual arran de les pregones diferències fraseològiques entre ambdós textos, i endemés viciada per una lesa interpretació de la font.

Ens interessa ara el motiu de l'endormiscament dels companys de Curial, i que hauria tingut com a model el de les Erínies a les Eumènides, el passatge concret del qual fa així: 


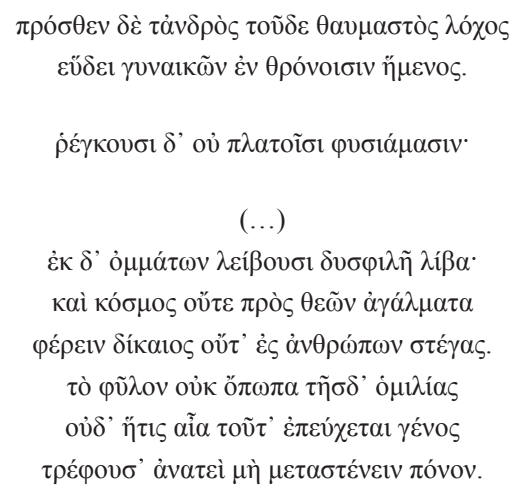

(A. Eum. vv. 46-47 i 54-59)

\begin{abstract}
I davant d'aquest home dorm assegut als escambells un portentós escamot de dones. (...) Ronquen amb bafarades que no fan de bon atansar; dels seus ulls degotegen un deixant fastigós. Decòrum no és capaç de guardar ni davant les efígies dels déus ni sota els sostres dels mortals. No be tingut davant dels ulls la raça d'aquest aplec, ni terra quisvulla no es vanta de pujar impunement aquesta raça per tal de no plànyer-se més tard pel seu afany.
\end{abstract}

El passatge del Curial que fa semblant d'haver-se inspirat al de les Eumènides diu el següent:

Los companyons seus, espaordits e plens de glay, callaren-se tots, e, defallint-los la força e la virtut, no pogueren anar avant, ans, espaordits, mirant-se los uns als altres se donaren causa de major por; car, veyen-se amb les cares mudades, tenyides de color de mort, muts e sense paraules, sens força e sens vigor e sens cosa que'ls consolàs ne'ls avivàs los spirits, e per ço forçats, hagueren [no] a seure, ans a jeure, no podent-se tenir en peus (Aramon i Serra 1933: III 33; l'esmena és nostra).

Aquí sí que trobem uns més clars indicis d'intertextualitat: encara que l’adjectiu grec $\theta \alpha v \mu \alpha \sigma \tau o ́ \varsigma$ no implica necessàriament l'experimentació d'un sentiment de por, ni actiu ni passiu, es pot entendre que l'autor del Curial ha interpretat la sensació de basarda i de fàstic que provoquen les Erínies de manera inversa a com la presenta Èsquil: els companys de Curial no causen la por de qui els veu, ans són ells mateixos víctimes atemorides de l'espaordiment. Hi ha una certa retirada, i tant, entre el passatge de la tragèdia dels seus ulls degotegen un deixant fastigós i el de la novella que parla de les cares mudades, tenyides de color de mort. Tanmateix, si bé la interrelació de les dues obres es dibuixa aquí amb una mínima nitidesa, tampoc no li atribuiríem la força d'una evidència.

El següent passatge que ens interessa el tenim als versos 64-66 de les Eumènides, on llegim el següent:

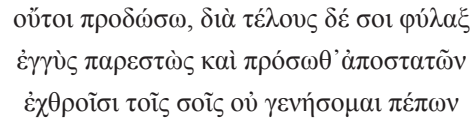

(A. Eum. vv. 64-66) 
Jordi Redondo. Èsquil al Curial e Güelfa

no t'he pas de trair, fins a la fi com a guardià, estant-te a prop com allunyat bona cosa, per a desgràcia dels teus aferrissats rivals no haig de ser tou

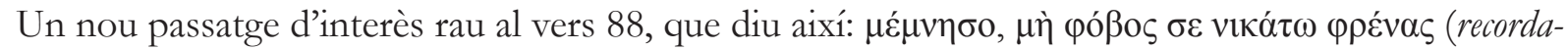
te'n, que la por no et venci l'esma).

Aquestes paraules són sempre ficades en llavis d'Apollo i adreçant-se en tots dos casos al jove Orestes, confòs i atemorit. Per la seua banda, al Curial e Güelfa l'heroi Hèctor acomboia el jove Curial amb les paraules següents:

\begin{abstract}
En aquell punt que Curial viu Hèctor, cuydà caure de la cadira on estava, e en lo seu cor se mès tanta terror, que tots los membres li començaren a tremolar. Mas aquell savi e cortès Hèctor, conexent la passió de Curial, apartant-se d'ell un poch, en la següent forma parlà: 'Curial, no'm maravell si has por veent-te entre tal gent constituït, car no ha vuy home en lo món que en tal plaça com aquesta se tengués per segur. Emperò sies cert que algun dels que aquí som no't pot tenir dan. Só estat certificat que tu'm desijaves veure; ve't m'aci; yo són aquell de qui tant se parla, e per ventura los fets meus no foren tals que tanta menció se'n degués fer. Si a mi fos possible fer alguna cosa per ta honor, no cansaria, mas és-me tolt, e a tu e a altre no pusc aprofitar; e aquesta és la pena que pas'.
\end{abstract}

La situació és semblant a totes dues obres, amb el protagonista atabalat per la seua inferioritat davant de personatges molt superiors, fins a ço que un d'ells el reconforta en assegurar-li el seu suport: «Si a mi fos possible fer alguna cosa per ta honor, no cansaria». No hi ha aquí una relació etimològica entre els termes emprats per Èsquil i per l'anònim autor de la novella catalana, però sí una de temàtica. Si les paraules d'Apollo eren, recordem-les, «no t'he pas de trair, fins a la fi com a guardià, estant-te a prop com allunyat bona cosa, per a desgràcia dels teus aferrissats rivals no haig de ser tou», és ara Hèctor el qui reprèn aquest missatge de lleialtat i protecció. Tanmateix, el lligam entre les Eumènides i el Curial e Güelfa no sembla consistent, de tan esvaït com queda arran de la dependència, no ja d'una relació semàntica, sinó d'una coincidència d'idees.

Aquest panorama intertextual canvia per complet si ens fixem en la frase «e en lo seu cor se mès tanta terror, que tots los membres li començaren a tremolar», que reprèn de manera molt aproximada la grega «recorda-te'n, que la por no et venci l'esma». La diferència es deu al fet que el discurs directe del parlament d'Apollo s'ha convertit en una frase inserida dins la narració, amb la qual cosa els dos imperatius, de gran força dramàtica, han esdevingut dos temps passats d'indicatiu

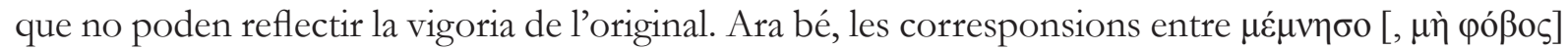

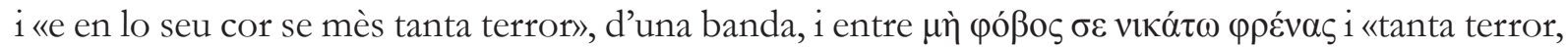
que tots los membres li començaren a tremolar», no s'expliquen sense l'acció de la intertextualitat. No pas una de directa, ans indirecta mitjançant la transposició d’una traducció o paràfrasi.

Un bon element per a escatir l'abast d'aquesta relació intertextual és el de l'Èsquil llatí de l'època, que amb tota seguretat va fer de mitjancer entre l'autor grec i el català. A l'època moderna, la traducció d'Ernst Anton Julius Ahrens destaca per la seua literalitat. Dels versos 64-66 ens dóna la 
versió «non te prodam, sed ad exitum usque custos tibi / et prope adstans et vero procul remotus / tuis hostibus non ero mollior», i del vers 88 «memor esto; timor animum tuum ne vincito» (Dindorf \& Ahrens 1877: 133). Però hem de plantejar el cas d'acord amb la tradició filològica i literària de l'època, mitjan segle XV. I doncs, si acudim a un diccionari de l'època del Curial, el del carmelità Giovanni Crastone, ${ }^{19}$ trobarem el verb $\mu \mu v \eta ̣$ $\sigma \kappa \omega$ traduït com a «commemoro i[d est] facio recordari» (Crastone 1497: 209). I que l'obra de Crastone -el primer diccionari greco-llatí imprès- féu forat ho demostra el diccionari de Valla, Barbaro i Poliziano, del 1532, amb la traducció «commemoro, id est, facio recordari» (Valla et al. 1532: 175). Amb algun afegitó trobem la mateixa traducció al Lexicon Graeco-Latinum publicat tambe el 1532 -curiosament- per Pierre Gilles, ço és, «commemoro, id est facio recordari, in memoriam evoco» (Gilles 1532: 261).

La relació semàntica -no pas etimològica, és clar- entre $\mu \mu v \eta ̣ ́ \sigma \omega \omega$ i recordar, fixada a la lexicografia de l'època, és la que dóna pas al text d'arribada «e en lo seu cor se mès» etc. Només el vers d'Èsquil permet d'explicar l'aparició, per transposició, del terme por, tot i que per alguna raó, on probablement hi ha tant o més de descurança que de malinterpretació, el sentit de l'original grec queda del tot desvirtuat: «que la por no et venci l'esma» es transforma en «tots los membres li començaren a tremolan». Per consegüent, el text del Curial no fa una traducció ni directa ni precisa del passatge d'Èsquil, però amb tota claredat en depèn. Ja hem explicat com l'eco dels versos 64-66 es troba sense gaires dificultats a les paraules d'Hèctor. Però l'adaptació del vers 88 esdevé diàfana i inequívoca. Barreja més matusserament que no acurada les dues frases que formen el vers grec, en fer del subjecte de la segona el de la primera, el que s'adiu amb la tècnica d'algú que no té com a objectiu la traducció, ans l'apropriació de motius literaris que contribuïssin a l'ornat de la seua obra. El resultat és un anostrament aproximatiu de l'original, mai a manera de traducció i sí més a prop de la paràfrasi. Així és com arribava a la literatura catalana el text del 458 a.C.

19 L'editio princeps del Lexicon Graeco-Latinum, que va inaugurar la impressió de diccionaris grecs, es va fer a Milà el 1478, però molts humanistes se n'havien procurar còpies manuscrites des de força anys abans. D'altra banda, els materials lexicogràfics arreplegats per Crastone representen una certa tradició traductora. 


\section{Bibliografia}

Aramon i Serra, R. (1930) Curial e Güelfa I, Barcelona.

—. (1933) Curial e Güelfa III, Barcelona.

Badia, L. (1986) «De la 'reverenda letradura' en el Curial e Güelfa», Caplletra 2, 1986, pp. 5-18.

Boehne, P. J. (1979) «The Coronation of Curial», Actes del Segon Col.loqui d'Estudis Catalans a NordAmèrica, Barcelona 1979, pp. 179-187.

- (1989) The Renaissance Catalan Novel, Boston.

Casarsa, L., d'Angelo, M. \& Scalon, C. (1999), La libreria di Guarnerio d'Artegna I-II, Udine.

Crastone, G. (1497) Lexicon Graeco-Latinum, Venècia, Aldo Manuzio ed.

Dawe, R.D. (1964) The collation and investigation of manuscripts of Aescbylus, Cambridge 1964.

Dindorf, W. \& E.A.I. Ahrens, E.A.I. (edd.), Aeschyli et Sophoclis Tragoediae et Fragmenta. Graece et Latine cum indicibus, París, Firmin Didot, 1877 (= 1842).

Espadaler, A. (1984) Una reina per a Curial, Barcelona.

Ferrer del Río, E. (2014) «La descripción y catalogación de fondos bibliográficos: la biblioteca del Duque de Calabria», Revista Historias del Orbis Terrarum 8, pp. 1-23.

Franceschini, A. (1976) Giovanni Aurispa e la sua biblioteca. Notizie e documenti, Pàdua.

Futo Kennedy, R. (ed.) (2017), Brill's Companion to the Reception of Aeschylus, Leiden \& Boston.

Geanakoplos, D. (1989) Constantinople and the West: Essays on the Late Byzantine (Palaeologan) and Italian Renaissances and the Byzantine and Roman Churches, Wisconsin UP 1989.

Giannini, A. M. (1973) The Manuscripts of Giovanni Aurispa (1376-1459), tesi doctoral, Chapel Hill.

Gilles, P. (1532) Lexicon Graeco-Latinum, Basilea.

Malvica, F. et al., Effemeridi scientifiche e letterarie per la Sicilia V, Palerm 1833.

Mancini, G. (1891) Vita di Lorenzo Valla, Florència.

Mioni, E. (1968), «Bessarione bibliofilo e filólogo», RSBN 15, 1968, pp. 61-83.

Ortolani, G.E. et al. (1818), Biografia degli nomini illustri della Sicilia ornata de' loro rispettivi ritratti II, Nàpols 1818.

Sabbadini, R. (1890) Biografia documentata di Giovanni Aurispa, Noto.

Sabbadini, R. (ed.) (1931), Carteggio di Giovanni Aurispa, Roma.

Salvo Cozzo, G. (1891) «A proposito di una nuova pubblicazione di Giovanni Aurispa», Giornale storico della letteratura italiana 18, pp. 303-312. 
Jordi Redondo. Èsquil al Curial e Güelfa

Schreiner, P. (1994), «Giovanni Aurispa in Konstantinopel. Schicksale griechischer Handschriften im 15. Jahrhundert», dins J. Helmrath et alii (edd.), Studien zum 15. Jahrbundert. Festschrift für Erich Meuthen, Munic 1994, pp. 623-633.

Simelidis, C. (2017), «Aeschylus in Byzantium», dins R. Futo Kennedy (ed.) (2017), pp. 179-202.

Ullmann, B. L. \& Stadter, P. (1972) The Public Library of Renaissance Florence: Niccolò Niccoli, Cosimo de' Medici and the Library of San Marco, Pàdua.

Valla, L., Erasmo, D., Barbaro, E., Poliziano, A.A. \& Rhodiginus, L.C. (1532), Lexicon GraecoLatinum, París. 